DOI: https://doi.org/10.24867/10FA09Stefanovic

\title{
MOGUĆNOSTI PRIMENE PARAMETARSKOG MODELOVANJA ARHITEKTONSKIH ELEMENATA PRILIKOM REKONSTRUKCIJE POSTOJEĆIH OBJEKATA
}

\section{POSSIBLE APPLICATIONS OF PARAMETRIC MODELING OF ARCHITECTURAL ELEMENTS DURING RECONSTRUCTION OF EXISTING BUILDING}

\author{
Katarina Stefanović, Fakultet tehničkih nauka, Novi Sad
}

\section{Oblast - DIGITALNI DIZAJN}

Kratak sadržaj - U radu je predstavljena implementacija perforiranih panela na objekte koji su bili rekonstruisani $i$ prostore koji su adaptirani. Takođe rad opisuje $i$ korišćenje Grasshopper-a, plug in-a za program Rhino koji služi za parametasko modelovanje, kao i primenu ovako modelovanih panela $u$ drugim programima za vizualizaciju ali i mogućnosti praktične pimene. Sama implementacija i način primene na praktičnim primerima su takođe detaljnije opisani kako bi se istražile $i$ ispitale mogućnosti koje ovakvo modelovanje pruža.

Ključne reči: Parametarsko modelovanje, Digitalni dizajn, Ornament, Digitalna fabrikacija, CNC, Paneli, Perforacija, Perforirane fasade, Enterijer.

\begin{abstract}
The paper presents the implementation of perforated panels on buildings that have been reconstructed and spaces that have been adapted. The paper also describes the use of Grasshopper, a plug-in for the Rhino program that is used for parametric modeling, as well as the application of such modeled panels in other visualization programs, but also the possibilities of practical use. The implementation itself and the way of application on practical examples are also described in more detail in order to explore and examine the possibilities that such modeling provides.
\end{abstract}

Keywords: Parametric modeling, Digital design, Ornament, Digital fabrication, CNC, Panels, Perforation, Perforated facades, Interior.

\section{UVOD}

Predmet istraživanja i predmet ovog rada se zasnivaju na rekonstrukcijama određenih objekata koji imaju i različite namene i koji u svojoj arhitekturi koriste perforirane parametarske elemente kako bi poboljšali svoj kvalitet eksterijerskog i enterijerskog uređenja ali i svoju funkciju. Takođe, istraživanje se zasniva na ispitivanju oblika perforacija i načina, kako bi se pronašla najbolja rešenja $u$ skladu sa okolnim parametrima i potrebama i kako bi se pronađeno rešenje učinilo lako promenljivo i time dobio lako promenljiv patern široke primene. Ono što se nalazi na fasadi a osim praktične ima i estetsku funkciju, može

\section{NAPOMENA:}

Ovaj rad proistekao je iz master rada čiji mentor je bio prof. dr Bojan Tepavčević. da se svrsta u ornament. Ornament je geometrijski stilizovana šara ili motiv iz prirode [1]. U savremenom oblikovanju fasada ističu se dva tipa nove ornamentike, ornamentika medijskih fasada i konstruktivna ornamentika. Grasshopper je dodatak (plug-in) progamu Rhino $i$ to je jedan od najčešće upotrebljivanih alata $u$ ovoj sferi modelovanja. On se sastoji od više skripti koje proces dizajniranja zasnivaju na parametarskom modelovanju, odnosno na parametrima koje dizajner zadaje [2]. U ovom radu, istraživanje o ornamentu $i$ kompjuterskim alatima koji se koriste za parametarko modelovanje dopriinelo je izboru gometrije i implementiranju iste na panele različitih materijala.

\section{PERFORIRANE I PARAMETARSKI MODELOVANE FASADE I FASADNI ELEMENTI U ARHITEKTONSKOM DIZAJNU}

Parametarski dizajn je proces zasnovan na algoritamskom razmišljanju koji omogućava izražavanje parametara i pravila koji zajedno definišu, kodiraju i pojašnjavaju vezu između svrhe dizajna i odgovora na dizajn.

Novi alati za dizajn igraju presudnu ulogu u omogućavanju parametarskog modelovanja, uspostavljajući potpuno novi proces i metodologiju dizajniranja. Parametrizam stoga zavisi od usvajanja i primene računarskih tehnika [9].

Prilikom primene parametarskog modelovanja na panelima u ovom radu, upotrebljeni su sistemi ograničenja, odnosno, definisani su parametri koji će uslovljavati geometriju panela. Parametarsko modelovanje je efikasnije od klasičnog modelovanja ukoliko se uoče i definišu potrebni algoritmi što i jeste njegova svrha. Složeni geometrijski problemi(oblici) koji su u nekom međusobnom poznatom odnosu se lakše rešavaju koristeći parametarsko modelovanje [8].

Postoji nekoliko faza u dizaniranju perforiranih površina: A.Definicija geometrije.

B.Organizacija elemenata, određivanje geometrije, deformacije $\mathrm{i}$ varijacije u veličini.

B. Raspodela elemenata ukoliko se koristi mapiranje ili rotiranje.

G. Stvaranje konačnog izgleda površine, odabir završne obrade, materijala i boje.

Prilikom kreiranja perforirane površine, postoje neke funkcije koje određuje dizajner i koje su međusobno povezane, parametri koje čine funkciju zapravo određuju kako će površina izgledati. Moguće je te promene kombinovati a moguće je i izabrati samo jednu. Cilj je da parametri koji određuju funkciju i funkcije koje određuju 
izgled elementa budu lako promenljive, da bi to bilo moguće, koriste se domeni koji su određeni brojčanim ili drugim vrednomstima.

\subsection{Perforirani fasadni paneli na javnim objektima} Poslovne zgrade su često dizajnerski rešavane perforacijom koja je prametasrki modelovana, na taj način postiže se željeni dizajn koji najčešće upućuje na namenu poslovanja objekta ili ispisuje direktan naziv kompanije.

Međutim, nije dizajn jedini razlog upotrebe perforiranih panela već je razlog uglavnom i to što je često potrebno obezbediti dovoljno svetla ali i dovoljno senke, zvučno izolovati objekat ili napraviti privatnije prostore.

Sakralni objekti su izazov za arhitekte širom sveta, strog, propisan, tradicionalni dizajn diktira na čemu će se zasnivati osnovni princpi dizajniranja.

Prilikom tog procesa, koriste se uglavnom tradicionalni materijali. Perforacija fasada ili delova na sakralnim objektima, mogu imati veliki pečat kako u spoljnom dizajnu ali isto tako i u unutrašnjem jer upravo senke koje se dobijaju perforacijom na fasadi, u enterijeru objekta mogu dobiti uzvišeni ton i tako stvoriti jedan prostor koji je autentičan, zaštićen od previše svetla i buke, ušuškan i ekonomičan.

Ugostiteljski objekti su u današnjem vremenu zastupljeni na javnim površina, u tržnim centrima a često $i \mathrm{u}$ privatnim objektima, na trgovima...

Nije lako ni jednom dizajneru da iskoristi dovoljno mašte i da formom ili enterijerskim rešenjem izdvoji neki od njih. Perforirani paneli su idealni za ovakve objekte, kada treba izdvojiti prostore, bašte, dati privatnost, zaštiti od buke ili previše setlosti, dati originalnost i privući pažnju. Objekti namenjeni obrazovanju su takođe objekti kod kojih je veoma zgodno i poželjno upotrebiti perforirane panele za fasadu.

Osim što je ovakvim objektima uvek veliki problem da reše osunčanost, bitan faktor pri projektovanju je i privatnost.

Treba biti veoma pažljiv prilikom projektovanja i dizajniranja objekata koji su namenjeni deci i mladima jer ono što u njihovom sećanju ostane kao lepo i u njima izazove prijatan osećaj, pratiće ih doživotno. Pristupačno, prilagođeno i prijatno je ono što deca treba da dožive tokom njihovog boravka u školama i vrtićima.

\subsection{Perforirani fasadni paneli na privatnim objektima}

Fasade na privatnim objektima se uvek stavljaju u drugi plan jer objekat ne teži da postane autentičan ili da vas prizove da uđete $u$ isti, već je sav fokus na enterijeru $i$ funkcionalnom rešenju osnova.

Da bi neki objekat ili kuća dobili fasadu koja odstupa od uobičajenih materijala i obrade, ta fasada mora da ima $\mathrm{i}$ dobru funcionalnu pozadinu i mora da ima lokaciju koja zahteva pažljivo postupanje sa fasadom.

Kada obloga na fasadi osim estetike ponudi i zaštitu od buke koja bi dolazila sa ulice što omogućava da lokacija objekta bude i u prometnim delovima grada ili kada nudi bolju energetsku efikasnost što smanjuje troškove grejanja i hlađenja objekta, kad fasadnim panelom stvorite privatnost i intimniji osećaj u kući i kada sunce bude sprečeno da nekontrolisano ometa svakodnevne aktivnosti u objektu, onda je izbor perforirane fasade zapravo idealno i ne toliko skupo rešenje.

\section{PERFORIRANI PANELI U ENTERIJERU}

Perforirani paneli su sve češći detalj modernih enterijera, osim dekorativne funkcije, imaju i mnogo drugih funkcija, pregrađivanje prostora, zvučna izolacija,...

Kroz nekoliko analiza, u ovom radu, istražio se odnos između funkcije i dekoracije, kada dekoracija ima veliki značaj za prostor a kada veći značaj ima funkcija. Perforirani paneli u enterijeru mogu biti od različitih materijala i izbor je mnogo veći nego za panele koji su izloženi spoljašnjim uticajima i vremenskim nepogodama, UV zračenju, itd...

\subsection{Perforirani paneli u privatnim objektima}

Paneli u privatnim objektima, kućama ili stanovima, najčešće su dizajnirani na osnovu ličnih afiniteta ili na osnovu toga šta nudi firma koja se bavi izvođenjem ovih radova. Perforirani paneli u etnerijeru se često koriste $\mathrm{i}$ kao ograde za stepenice, zatim za pregrađivanje prostora između kuhinje i dnevnog boravka, između radnih i privatnih prostora. Najčešće izabrani materijal je medijapan a boje se protežu od onih prirodnijih i $\mathrm{u}$ tonu drveta, do jarkih i sjajnih boja.

\subsection{Perforirani paneli u javnim objektima}

Javni objekti su uvek scpecifična vrsta objekata jer ih koristi mnogo veći broj ljudi, shodno tome, biraju se materijali, boje, funkcije i dizajn perforiranih panela. Pod javne objekte gde često mogu da se primene perforirani paneli spadaju sve ustanove obrazovnog karaktera, bolnice, državne zgrade, gradske ustanove, pozorišta, muzeji, biblioteke, koncertne sale...

Sve bolje performanse materijala poput zvučne izolacije, podstakle su sve češću upotrebu perforiranih panela.

\subsection{Perforirani paneli u poslovnim objektima}

Ova tipologija objekata je najzanimljivija jer se može uočiti neka vrsta arhitektonskog i dizajnerskog takmičenja $\mathrm{u}$ originalnosti izbora perforacije, materijala i luksuznosti. Kroz analize primera, uočava se da je dizajn usko povezan sa delatnošću. Firme koje se više bave marketingom, teže da njihov dizajn bude zasnovan na prepoznatljivosti, ugostiteljski objekti teže ka eleganciji, itd...

\section{MATERIJALI KOJI SU POGODNI ZA IMPLEMENTIRANJE PERFORACIJE}

$\mathrm{Na}$ konačan izgled fasade osim geometrije veliki uticaj imaju materijali i boje. Materijal koji se za fasadu bira usko je povezan sa dizajnom fasade. Većina perforiranih fasada jednostavne ili složene geometrije napravljene su od metala. Fasade od stakla obično ne mogu da budu perforirane već se za njih češće koriste štampani ornamenti. Za zidane fasade se koristi opeka kako bi se perforacija postigla i stvorila igra punoće, praznine i pokreta. Izbor materijala može imati veliki uticaj na odabir i organizaciju algoritma tako da se boja i materijal najčešće biraju u odnosu na uslove koje geometrija postavi, na kraju procesa dizajniranja, a za cilj imaju da daju konačni izgled modelu. U savremenoj arhitekturi bojama često nije posvećeno dovoljno pažnje, a sofisticiran izbor boje zgradi može da da karakter. Boja može da naglasi neke delove fasade a može da naglasi i celu fasadu. 


\subsection{Metal}

Perforirani metal se u ranoj istoriji koristio u vojne svrhe, u svrhe kovanja novca ali nisu nepoznati primeri gde je perforirani metal, iako je bilo potrebno mnogo napora da se izradi, služio za ukras.

Prve mašine za perforiranje metala pojavile su se sredinom i krajem 1800-ih.

Početkom 2000-ih perforirani metal ušao je u novu fazu svoje istorije $\mathrm{i}$ od tada se širi korišćenjem digitalnih tehnologija za razvoj perforacije.

Inovacija perforacije panela dovela je do mnogih mogućnosti i u estetici i u funkciji. U narednih deset godina, od 2005. do 2015. godine, počelo je da se otkriva novo istraživanje $u$ fasadnim tehnologijama [3].

Od metala, najčešće se koriste lim, aluminijum, gvožđe, bakar , a u sve češćoj primeni je i cink.

Nerđajući čelik je jedan od najekološkijih metala. Ukoliko se izabere dobar čelik kao i njegova završna obrada, uz pravilno održavanje, on će ostati nepromenjen tokom celog životnog veka objekta potrajao on i nekoliko stotina godina.

Nerđajući čelik je više otporniji na koroziju od drugih uobičajenih arhitektonskih metala i na njega ne utiču neki zagađivači koji bi ih korodirali kao što su azotna kiselina, ugljena kiselina, amonijak koji se mogu naći u kiselim kišama.

Aluminijum je jedan od metala koji je dosta teško seći ali ukoliko je debljina istog ispod $6 \mathrm{~mm}$ upotrebom adekvatnih hemijskih jedinjenja, moguće je iseći aluminijum CNC sečenjem. Slično aluminijumu, bakar i bronza imaju određena svojstva koja otežavaju njihovo sečenje, dok se titanijum perforira na nešto jednostavniji način.

\subsection{Drvo i drvne prerađevine}

Nekada je drvo korišćeno mnogo više jer je bilo lako dostupno, jeftino, dugotrjano. Danas se drvo koristi manje jer su pronađeni drugi materijali sa sličnim ili boljim performansama. Međutim, drvo počinje da ponovo „ulazi u modu, jer njegovu toplinu, rustičnost i sve bolje performanse, savremeni materijali ne mogu da zamene.

Često se za perforirane fasade i panele koriste HPL (High Pressure Laminates) kompaktne ploče.

Kompaktne ploče su laminati debljine $2 \mathrm{~mm}$ do $20 \mathrm{~mm}$, od više slojeva vlaknastog celuloznog materijala (papira) velike gustine. Izrađuju se lepljenjem papirnih folija impregniranih termoreaktivnom smolom koje se presuju na visokim temperaturama i pod visokim pritiskom, što osigurava dovoljno očvšćivanje.

MDF (eng. Medium-density fiberboard) vrsta je tehničkog drveta proizvedena od drvenih vlakana lepkom spojenih u konzistentnu masu pod visokim pritiskom. Kao sirov materijal ima nedovoljnu estetsku vrednost, no razni premazi, boje i furniri mogu se aplicirati na površinu te na taj način rišiti problem estetike [6].

\subsection{Opeka}

Opeka je materijal koji je moderan veoma dugi niz godina i zbog toga što se idalje istražuje, interesantan je arhitektama širom sveta za nove oblike i perforacije. Česti su primeri gde se slaganjem opeke postizalo mnogo efekata i funkcionalne i estetske vrednosti. Opeka se u savremenoj arhitekturi koristi tako da joj se ističe estetska vrednost sa akcentom na tradicionalnom.

Prilikom izvođenja perforiranih zidova od opeke prednost u odnosu na ostale materijale je ta što opeku nije potrebno dodatno obrađivati, seći, već je dovoljno samo je rotirati i povezati na uobičajen način.

\subsection{Staklo}

Staklo je materijal koji je vrhunac u dizajnu dostigao krajem XX veka. Stalna istraživanja dovela su do toga da staklo počinje da se orađuje tako ad se stvaraju konkavni i konveksni oblici ali velikih formata. Nema mnogo primera foriranja perforiranih zidova i panela od stakla, ali su zato izvedeni primeri, fascinantni.

\subsection{Plastika}

Plastika i plastične mase se često koriste u arhitekturi, najviše u dizajnu enterijera. Zanimljivi su premeri i fasada koje su rešene plastičnim pločama i to postaje sve češći vid oblaganja. Plastika je vremenom napredovala, istraživači su uz pomoć hemijskih jedinjenja i novih materijala, plastici dodavali aditive i dobijali materijal sa novim i boljim performansama.

FRP ploče imaju odlične performanse, dugotrajne su, čvrste, postojane, daju slobodu u dizajniranju, ne lome se lako a težina im je mala. Ovi materijali imaju dobru toplotnu izolaciju, otpornost na UV zračenje, požare i hemikalije. One se koriste čak i za ojačavanje greda, stubova, mostova [7].

\section{5. ТЕХНОЛОГИЈА И НАЧИН ПРОЗВОДЫЕ ПЕРФОРИРАНИХ ПАНЕЛА}

Digitalno doba omogućilo je direktnu digitalnu vezu između onoga što se može predstaviti i onoga što se može izgraditi kroz procese ,file-to-factory (od fajla do fabrike)“. Ovakvi načini funkcionisanja projekta, efikasni su jer arhitekte mogu pratiti fajlove na osnovu kojih se dešava cela proizvodnja a koje su prethodno morali da adaptiraju za proces proizvodnje.

\subsection{CNC obrada}

Ovakva obrada materijala zasnovana je na tome da kompjuter upravlja celim procesom. CNC(Computer Numerical Control) rezanje, ili dvodimenzionalna izrada, najstarija je i najčešće korišćena tehnika izrade koja uključuje jednostavno pomeranje glave sečenja u dve ose $\mathrm{u}$ odnosu na materijal. Tehnologije sečenja, zasnovane na pregrejanim gasovima (plazmeni luk), laserskom svetlu i vodenom mlazu pod vi sokim pritiskom, široko su dostupne i intenzivno se koriste. Najčešći režimi obrade koje izvode CNC mašine su: glodanje, bušenje, tokarenje i rezanje (plazmom, laserom, mlazom vode. Za razliku od manualnih mašina na kojima je čovek izrađivao predmete prema tehničkom crtežu upravljajući polugama i koloturima, CNC mašine obavljaju radne operacije prema kodu koji je generisan uz pomoć CAM softera iz CAD crteža. Prema broju stepeni slobode gibanja glave mašine razlikujemo 2,3,4, 5 i 6 -osne CNC mašine.

Najčešće korišćene mašine su one koje idu u dve ose. U CNC glodanju, mašine dodaju mogućnost pomeranja glave duž treće ose [4]. 


\subsection{D štampa}

3D štampanje (eng.3D printing) je savremeni termin koji predstavlja stvaranje nekog objekta putem slaganja slojeva gradivnog materijala. U okviru ove tehnologije, postoje različite tehnike i materijali kojima se to postiže. 3D štampa omogućuje izradu predmeta kompleksnih formi, funkcionalnih prototipa, i gotovih proizvoda prema visoko preciznim specifikacijama. Plastična masa kojom se izrađuje objekat može biti različitih osobina- od biorazgradivih masa sa ekološkim oznakama, do plastika koja je visoko otporna na udarce i temperature i može se čak koristiti u industriji rezervnih delova.

Sve tehnologije 3D štampe se baziraju na principu aditivne proizvodnje, sloj po sloj. Štampajuća glava, nanosi gradivni materijal $\mathrm{i}$ onda se sve pomeri za stepen vertikalno, kako bi se naneo sledeći sloj [5]. Načini štampe su različiti, i može se izdvojiti više različitih načina 3D štampe.

\section{REKONSTRUKCIJA, ADAPTACIJA, DOGRADNJA}

\subsection{Rekonstrukcija privatnog objekta i upotreba pefroriranih panela}

U pitanju je rekonstrukcija jednoporodičnog objekta $u$ višeporodično stanovanje za tri porodice i adaptacija objekta za novu upotrebu. S obzirom da se funkcija objekta menja, menja se raspored prostorija a sa rasporedom se menjaju otvori, adaptiraju stari i otvaraju novi. Shodno funkciji novog objekta, bilo je neophodno analizirati i preurediti izgled fasade. Na novoj fasadi su se javili prozori koji nisu postojali ranije, sa ulične strane. Novi zadatak je bio kako rešiti privatnost u sanitarnim čvorovima, da ostanu funkcionalni i da ne narušavaju izgled fasade. Element koji bi bio na fasadi, treba da bude i zastor, propusnik svetlosti i vazduha ali i ukras. Najviše privatnosti su tražili prozori od sanitarnih čvorova a s obzirom da su oni i najmanji prozori na fasadi te tako narušavaju skladnost portala, ideja da se oni prekriju perforiranim panelima je bila potkovana sa više različitih apekata.Cilj je bio pronaći šaru koju će biti moguće izvesti, skladnu i da prenese deo enterijera starog objekta. Generisanje oblika je bilo veoma zahtevno kao i mogućnost stvaranja parametarskih funkcija za perforaciju koje bi bile promenljive.

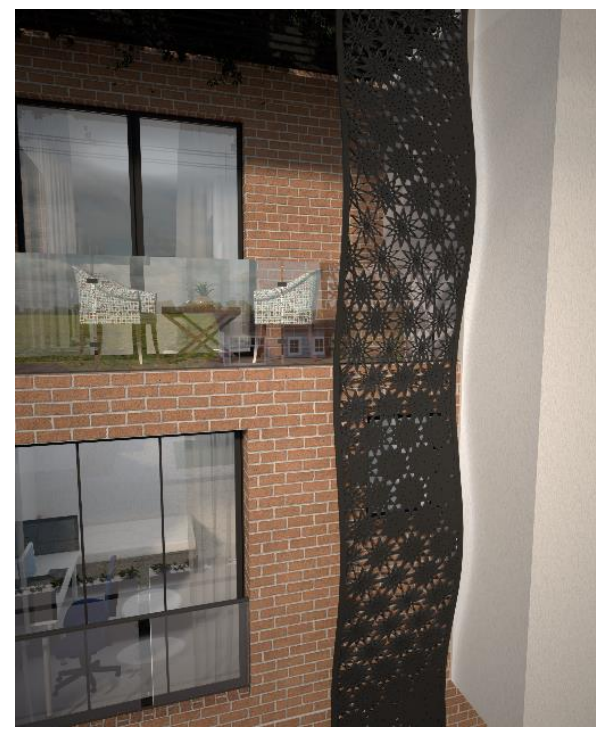

Slika1-3D prikaz perforiranog panela

\subsection{Adaptacija stamenog prostora u stambeno poslovni prostor}

Sve veću potrebu za višenamenskim prostorima doneo je savremeni način života.

Potrebe investitora su te da postoji odvojen prostor za rad ali koji se može adaptrati tako da postane i deo stambenog prostora, deo dnevnog boravka.

Što se hodnika tiče, bilo je potrebno da hodnik postane takođe deo poslovnog dela onda kada je to potrebno i obrnuto, da postane deo stambenog prostora kada se radno vreme završi.

Zid koji deli spavaću sobu i dnevnu sobu, predviđen je da se sruši kako bi se ovi prostori povezali i da se umesto zidanog zida napravi perforirani zid na šinama koji bi se sastojao od tri pokretna panela koja bi se kretala po tim šinama po potrebi.

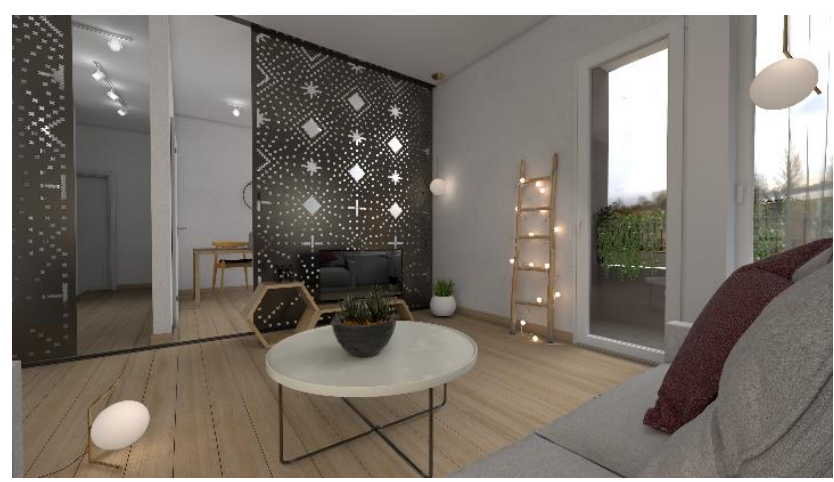

Slika 2-3D prikaz panela u enterijeru

\subsection{Nadogradnja dečijeg vrtića i upotreba} perforiranih panela na fasadi

Dečiji svet je šaren, bezbrižan i veseo, s toga i projektovanju treba pristupiti na taj način. Projektni zadatak je nadogradnja postojećeg vrtića i obezbeđivanje energetske efikasnosti celog objekta .

Ideja za uvođenje perforiranih panela je nastala $u$ onom trenutku kada je bilo neophodno postaviti znatno veće prozore u sobama radi minimalne količine svetla koja bi u prostor ušla. Te velike prozore trebalo je zaštiti iz bezbednosnih razloga ali i napraviti prostore unutra više prijatnim za boravak i intimnijim.

Fasada koja se mogla izvesti nakon oblaganja stiroporom, a da je finansijski bila prihvatljiva je demit fasada bele boje. Paneli bi na ovaj način monotonu i jednoličnu belu fasadu učinili zanimljivom i autentičnom.

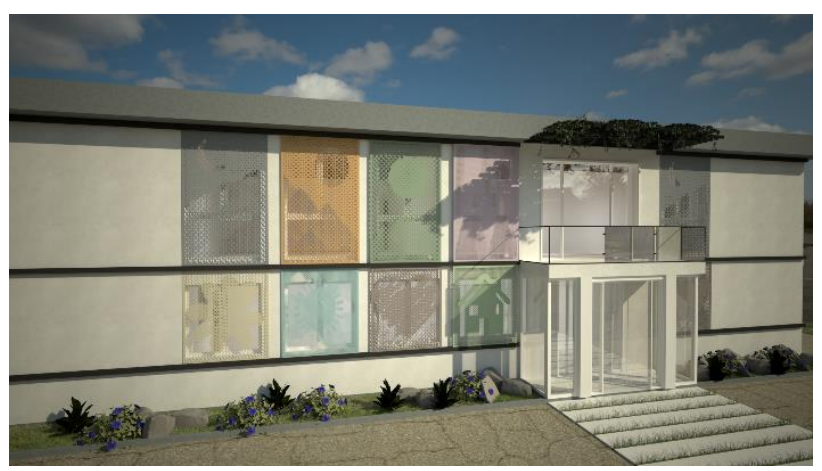

Slika 3- Perforirani paneli na prozorima 


\section{ZAKLJUČAK}

Glavni cilj ovog rada bio je razviti metodologiju koja pomaže arhitektama za generisanje perforiranih fasada i panela koristeći algoritamski pristup dizajniranju i kako primeniti ovu metodologiju kada ne stvaramo od početka već imamo zadata ograničenja u vidu nepromenljivih uticaja ali i u vidu uticaja koje možemo promeniti kao što su eventualne želje investitora.

U radu, istraživanje je bilo zasnovano na fazama dizajna koje čine algoritamski pristup za generisanje fasade građevina, a iz tih faza proističe i klasifikacija fasada koja može da predstavlja početak nekog procesa dizajna i pomoćno sredstvo u odabiru algoritma u skladu sa zahtevima projekta. U toku istraživanja geometrije paterna, uočeno je koliko mogućnosti postoji i koliko je dobro imati podlogu, kod, koji se može implementirati kasnije na bilo koji projekat.

Korišćeni programi su se pokazali kao veoma efikasni i kao alati koji mogu poslužiti ubuduće za ovakve projekte. Što se geometrije elemenata perforacije tiče, na fasadi jednoporodične kuće i vrtića, istraživanje je sprovedeno do kraja i kodovi koji u napravljeni imaju mnogo promenljivih komponenti, što pruža korisniu da bolje i detaljnije sagleda panele, menja ih i istažuje ih.

Što se tiče enterijerskog panela, geometrija je dosta zavisila od dimenzije panela, pa svaka promena mora biti proporcionalna obliku panela. Izmene i mogućnost da ovaj kod bude fleksibilan a da geometrija ostane ista su izostale . Detaljne analize materijala, omogućile su što bolji odabir pravih materijala u skladu sa upotrebom i sa geometrijskim oblicima koji su trebali da se apliciraju.

Tokom istraživanja materijala, uočene su neke novine koje daju odlične performanse osnovnim materijalima. Širok spektar materijala i za spoljnu i za unutrašnju upotrebu omogućavaju slobodniji i bezbrižniji izbor. Što se tiče fabrikacije panela, istraženo je više mogućnosti i primećeno je da su načini na koji se stvaraju ovakvi arhitetonski elementi, sve dostupniji. Istraživanja u ovom radu mogu pomoći u sistematičnijem pogledu na perforacije i geometriju i olakšati dizajnerima izbor.
Ono što treba istražiti u budućim radovima jeste stvaranje fleksibilnijih kodova i eventualno fabrikacija probnog modela.

\section{LITERATURA}

[1] Sajt opšteg obrazovanja

https://www.opsteobrazovanje.in.rs/sta-znaci/ornament/

[2] Grasshopper sajt

https://www.grasshopper3d.com/

[3] Istorija metala

https://www.azahner.com/blog/history-of-perforated metal/

[4] CNC obrada

https://perfom.rs/kapacitet/

[5] 3D štampa

https://www.3drepublika.com/poredenje-3d-stampe-cncizrade/

[6] Materijali

https://www.bruag.com/materials/

[7] Plastika

http://papers.cumincad.org/data/works/att/3826.content.pdf

[8] Journal of Building Performance, Parametric architecture in it's second phase of evolution

[9] Parametric Design: a Brief History Stephen Phillips, $\mathrm{PhD}$

\section{Kratka biografija}

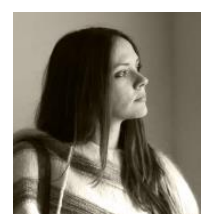

Katarina Stefanović rođena je 1993. godine Paraćinu. Fakultet tehničih nauka u Novom Sadu je upisala 2012. Godine a 2017.godine master program Digitelne tehnike, dizajn i produkcija u arhitekturi i urbanizmu.

kontakt: stefanovicketi@gmail.com 